\title{
MODEL APLIKASI E-MARKET SEBAGAI SARANA PROMOSI DAN TUKAR MENUKAR INFORMASI ANTARA PENJUAL DAN PEMBELI
}

\author{
Frans Richard Kodong, Wilis Kaswidjanti, Arif Setiyawan \\ Prodi Teknik Informatika UPN "Veteran" Yogyakarta \\ Jl. Babarsari 2 Tambakbayan 55281 Telp (0274) 485323 \\ email : frkodong@gmail.com
}

\begin{abstract}
With the Internet can facilitate human life in all areas, not least in the field of buying and selling and promotion, where the internet buying and selling process can be done more easily, for those sellers can easily Promote goods that are sold to consumers that they can easily find items needs, but to create a website selling a store still require substantial funds, and therefore required a new method in the business world, the market because the process is done electronically using electronic media and the internet is a method of electronic stores. The methode is to collect various types of shops into a website. In this application there is a facility newsletter that can be commented on by the other accountowners. In this way the expected communication between sellers and buyers and store owners to one another more closely, so that in terms of social aspects and the business is very profitable because it can add to relationships and friendships. This application will be made using the language of the webbased pemorgraman JSP and servlets, jquery andajax as a transport request to the MySQL database as the media supported penyimpanadata. The method used in making this application is GRAPLLE. E-market applications asa container or a place and means of promotion and inforamasi exchange between sellerand buyer, in line with advances in technology to achieve their social and economic needs of human beings, so that economic growth particularly medium rise, because the e-marketthrough the application of this variation and reach a wider market, this is due to the use ofinternet technology that knows no time and space.
\end{abstract}

Keywords: Java Server Page, AJAX, Servlet, E-Marketplace

Dengan adanya internet dapat mempermudah kehidupan manusia dalam segala bidang , tak terkecuali dalam bidang jual beli dan promosi, dimana dengan internet proses jual beli dapat dilakukan lebih mudah, bagi penjual mereka dapat dengan mudah mepromosikan barang yang di jual bagi konsumen mereka dapat dengan mudah menemukan barang yang dibutuhkannya, namun untuk membuat sebuah website penjualan suatu toko masih membutuhkan dana yang besar, oleh karena itu dibutuhkan satu metode baru dalam dunia bisnis, yaitu elektronik market karena prosesnya dilakukan menggunakan media elektronik dan internet yaitu dengan metode elektronik toko. Metode tersebut dengan mengumpulkan berbagai jenis toko kedalam sebuah website. Dalam aplikasi ini terdapat fasilitas newsletter yang dapat dikomentari oleh pemilik account lainnya. Dengan cara ini diharapkan komunikasi antara penjual dan pembeli serta pemilik toko satu dengan yang lain lebih erat, sehingga ditinjau dari aspek sosial dan bisnis ini sangat menguntungkan karena dapat menambah relasi dan pertemanan. Aplikasi ini akan dibuat menggunakan bahasa pemorgraman berbasis web yaitu JSP dan servlet, jquery dan ajax sebagai transport request dengan didukung database MySQL sebagai media penyimpana data. Metode yang dipakai dalam pembuatan aplikasi ini adalah GRAPLLE. Aplikasi e-market ini sebagai suatu wadah atau tempat dan sarana promosi dan pertukaran inforamasi antara penjual dan pembeli, sejalan dengan kemajuan teknologi untuk mencapai kebutuhan sosial dan kebutuhan ekonomi manusia, sehingga pertumbuhan ekonomi khusunya menengah kebawah meningkat, karena lewat aplikasi e-market ini variasi dan jangkauan pasar lebih luas, hal ini disebabkan penggunaan teknologi internet yang tidak mengenal ruang dan waktu.

Kata kunci : Java Server Page, AJAX, Servlet, E-Marketplace 


\section{PENDAHULUAN}

Sejak zaman dahulu manusia menjadikan pasar sebagai suatu tempat untuk melakukan transaksi perdagangan baik barang atau jasa antara penjual dan pembeli dari produsen ke konsumen dengan tujuan untuk memenuhi kebutuhan masing-masing. Peranan Pasar dalam kehidupan manusia sangatlah penting, karena pasar menjadi tempat tujuan konsumen untuk mencari barang konsumsi langsung dari produsen atau distributor sehingga harga masih jauh lebih murah di bandingkan dengan harga toko, kios atau supermarket. Dalam pasar banyak terjadi aktivitas ekonomi dari mulai pemasaran, penawaran dan transaksi barang atau jasa. Dalam pasar terdapat juga aktivitas sosial yang manjadi bagian dari pasar, komunikasi tukar menukar informasi yang bertujuan untuk mencari relasi dan memudahkan antara penjual dan pembeli dalam melakukan transaksi jual beli. Aktivitas ekonomi yang terdapat didalam pasar seperti pemasaran, merupakan salah satu tahapan penting dalam proses bisnis, karena dalam tahapan ini barang ataupun jasa langsung atau secara tidak langsung dikenalkan kepada konsumen dengan strategi pemasaran melalui, advertising, brochures, public relation, tradeshow, direct sales, personal selling. Penawaran, merupakan salah satu proses pembentukan harga antara penjual dan pembeli, dalam proses ini secara tidak sadar terjadi aktivitas sosial yaitu tukar menukar informasi sehingga menimbulkan hubungan relasi yang lebih dalam dan kental. Pasar di Indonesia sangat banyak dan tempatnya tersebar dari kota sampai ke pelosok desa di seluruh wilayah Indonesia dengan jenis dan komoditas yang berbeda beda. Untuk mengakomodasi peranan pasar dan menambah variasi dan jenis pasar yang sudah ada serta mendukung proses dan kegiatan yang ada didalam pasar dari proses penawaran sampai proses pemasaran perlu di pikirkan strategi baru yang bisa mengatasi beberapa masalah yang muncul yaitu jarak pasar yang jauh, waktu yang terbatas, perbedaan komoditas antara pasar satu dengan yang lain, serta hambatan lain yang membuat penjual dan pembeli tidak bisa bertemu secara langsung atau terbatasnya waktu transaksi dan pemasaran oleh produsen atau penjual yaitu dengan internet.

E-Market memanfaatkan media digital seperti internet untuk menciptakan suatu lingkungan atau tempat yang mewadahi para penjual dan pembeli untuk melakukan proses proses bisnis mulai dari pemasaran produk, penawaran produk, mengembangkan komunikasi antara penjual dan pembeli sehingga tercapai kepuasan terhadap keduanya. E-Market sebagai tempat bertemunya penjual dan pembeli secara online mempunyai manfaat diantaranya, memperluas jaringan dan meningkatkan penjualan khususnya bagi usaha kecil dan usaha mandiri yang bermodal menengah ke bawah ataupun wira usaha baru yang sedang merintis bisnis atau usahanya, e- market sangat cocok untuk sarana penjualan mengenalkan produk bahkan menjaga komunikasi dan memperbanyak relasi, karena tidak membutuhkan biaya yang besar seperti halnya membuat pasar secara fisik, e-market tidak terbatas oleh waktu dan kondisi geografis bisa diakses dimana saja dan kapan saja sehingga sangat bagus untuk peningkatan penjulan dan pengenalan produk di lingkup yang lebih luas. Sejalan dengan kemudahan dan kemajuan teknologi internet serta untuk menciptakan variasi pasar yang berbasis teknologi, mempermudah orang untuk melakukan transaksi bisnis tanpa dibatasi ruang dan waktu, meningkatkan komunikasi sosial serta mendorong pertumbuhan ekonomi khusunya ekonomi menengah kebawah karena aplikasi e-market sangat cocok untuk pengusaha kecil dan baru mulai usahanya, aplikasi e-market yang memanfaatkan teknologi internet serta bertujuan menyatukan berbagai penjual dalam satu website dimana setiap penjual bisa mempromosikan produknya dengan cara meng-upload photo produk dan detail dari produk dalam halaman khusus tersendiri berdasarkan kategori produk yang diinginkan. member dari aplikasi ini dapat berkomunikasi lewat pesan layaknya e-mail, mengomentarai newsletter, mengomentari produk, memberikan testimoni kepuasan, semua fasilitas itu di buat supaya terjadi interaksi sehingga tercipta pertukaran informasi antara penjual dan pembeli secara langsung.

\section{TINJAUAN PUSTAKA}

\subsection{E-Market}

Dunia maya yang tercipta karena berkembangnya teknologi internet, secara tidak langsung membentuk sebuah pasar atau arena perdagangan tersendiri yang kerap dinamakan sebagai e-Marketplace (beberapa praktisi manajemen menyebutnya sebagai Marketspace). 
Sebagaimana pasar dalam pengertian konvensional, yaitu tempat bertemunya penjual dan pembeli, di dalam e- Marketplace berinteraksi pula berbagai perusahaan-perusahaan di dunia tanpa dibatasi oleh teritori ruang (geografis) maupun waktu. Beragam produk dan jasa dalam berbagai bentuknya dicoba ditawarkan oleh perusahaan-perusahaan yang telah "go internet" ini dalam berbagai domain industri, sehingga menghasilkan suatu nilai dan volume perdagangan yang tidak kalah besar dari pasar konvensional (Indrajit,2011).

\subsection{JSP ( Java Server Page )}

JSP (Java Server Page) merupakan teknologi yang didasarkan pada bahasa java, yang dapat digunakan untuk membentuk halaman-halaman Web yang bersifat dinamis. Teknologi ini dikembangkan oleh Sub Microsystems. Berbeda dengan applet, suatu fitur pada bahasa Java yang memungkinkan pengembang membuat aplikasi Web yang dieksekusi pada sisi klien, JSP menggunakan pendekatan pemrosesan di sisi server. Salah satu keuntungan model seperti ini adalah memungkinkan untuk membuat aplikasi yang independen terhadap keberadaan sistem Java di sisi klien.

\subsection{Servlet}

Servlet adalah teknologi java untuk aplikasi web. Teknologi servlet merupakan salah satu teknologi penting dari JEE (Java Enterprise Edition) karena menjadi dasar dari JSP (Java Server Page). Saat ini teknologi Java dapat dikatakan telah mendominasi teknologi enterprise karena teknologi ini terbukti tangguh dan stabil dalam aplikasi enterprise (JEE). Teknologi enterprise tersebut seringkali memanfaatkan interface web. Servlet sering digunakan untuk menghasilkan respone berupa halaman HTML, XML, file, dan sebagainya sesuai request yang berjalan pada protokol HTTP.

\section{METODE PENELITIAN}

Metode pengembangan menggunakan GRAPPLE dengan tujuan dapat menghasilkan sistem berorientasi objek dalam waktu yang singkat tanpa mengurangi kualitas sistem yang dibangun. GRAPPLE adalah sebuah pemodelan proses dalam pengembangan software yang menekankan pada aksi-aksi yang dilakukan pada sejumlah tahapan, setiap tahap akan menghasilkan produk kerja dengan bentuk yang berorientasi objek (Schmuller, 1999). Segmen yang terdapat dalam GRAPPLE tidak disusun dalam bentuk yang statis sehingga setiap segmen dapat dikerjakan berulang kali dengan urutan kerja yang tidak harus sesuai dengan urutan yang ada. Segmen-segmen yang digunakan dalam GRAPPLE mencakup analisis kebutuhan sistem, pengembangan model dan diagram, pembuatan kode hingga segmen instalasi dan evaluasi.

\section{Requirements Gathering}

Dalam segmen ini dilakukan analisis terhadap masalah, fungsi dan komponen produk yang akan dibuat (system requirements). Hasil dari segmen ini adalah sebuah dokumen kebutuhan yang akan dibahas Dalam tiga tahapan, yaitu analisis sistem, analisis kebutuhan pengguna dan analisis domain.

\section{a. Analisis Sistem}

Sistem Penjualan dengan memanfaatkan pasar secara fisik atau tradisional masih menimbulkan beberapa masalah yang sering dihadapi oleh penjual dan pembeli antara lain keterbatasan waktu, interaksi yang kurang antara kedua pihak, letak geografis yang berbeda, perbedaan jenis komoditas. Belum lagi permasalah-permasalahan lainnya yang dapat menyebabkan terhambatnya proses penjual dan pembeli bertemu didalam pasar. Berikut merupakan beberapa kebutuhan sistem yang ada, yaitu:

1. Memerlukan suatu media alternatif yang dapat menekan biaya modal.

2. Memerlukan suatu media alternatif yang dapat mengurangi jumlah pekerja, yaitu sebuah sistem e-market yang dikelola oleh member itu sendiri dan seorang admin.

3. Memerlukan sebuah media informasi e-market yang dapat mempromosikan produk secara online, agar ruang lingkup customer semakin luas tanpa batas ruang dan waktu asal terhubung dengan internet.

4. Memerlukan sistem yang telah terkomputerisasi. Agar data dari proses promosi dan komunikasi penjualan dapat disimpan secara aman dan dalam proses pencarian mudah ditemukan.

5. Memerlukan suatu media yang interaktif yang memungkinkan terjadinya komunikasi yang realtime dan intens antara penjual dan calon pembeli sehingga komunikasi berjalan dua arah atau lebih. 
b. Analisis Kebutuhan Pengguna

Berdasarkan analisis sistem diatas tersebut maka perlu dibangun sebuah Aplikasi $E$ Market sebagai wadah atau sarana penjualan, promosi, komunikasi dan tukar menukar informasi antara penjual dan pembeli. Berikut merupakan beberapa kebutuhan pengguna, yaitu:

1. Member dapat melihat info penawaran produk dan melihat informasi penjual secara lengkap.

2. Member dapat melakukan komunikasi terhadap penjual tanpa batas ruang dan waktu

3. Member dapat membuat newsletter yang nantinya memberikan informasi pada member lain tetang update informasi terbaru tentatang produk atau lainnya.

4. Member dapat menjadi pembeli atau penjual tergantung kebutuhan yang di inginkan oleh member.

5. Tiap member dapat menjadi teman dari member lain melaluai fasilitas add Partner bussines sehingga lebih mudah dalam memberikan update informasi atau komunikasi antar member.

6. Member dapat mempromosikan secara langsung produknya lewat fasilitas penjual atau want to sell yang isinya memberikan informasi barang yang ingin dijual kepada member lain.

7. Member dapat mencari barang tertentu dengan spesifikasi yang diinginkan oleh member ,yaitu lewat fasilitas pembeli atau want to buy .

8. Member dapat memberikan komentar terhadap newletter dan produk member lain yang sudah menjadi partner bussines nya .

9. Member dapat memberikan testimony kepada member lain yang menjadi partner bussines nya, testimoni sebagai bentuk kepuasan atas kerjasama antar member.

c. Analisis Domain

Aplikasi E-Market ini bertindak sebagai media bertemunya antara penjual dan pembeli, promosi dan komunikasi antara penjual dan pembeli yang didalamnya terdapat fasilitas fasilitas yang memungkinkan terjadinya proses transaksi bisnis, promosi dan komunikasi secara langsung seperti model jejaring sosial dan semua dikelola oleh admin yang mengendalikan sistem dari aplikasi E-Market ini. Aplikasi ini memiliki tiga aktor, yaitu member, user dan admin. User atau pengunjung dapat melihat atau mengakses informasi profile member, produk member, melihat want to sell ,melihat want to buy, melihat produk berdasar kategori , melakukan proses pencarian, tapi user tidak bisa memberikan komentar produk atau newsletter dan fasilitas lainnya yang hanya bisa dilakukan oleh member yang terdaftar. Member menjadi kunci dalam aplikasi E-market ini karena member yang melakukan proses bisnis secara langsung dan tidak langsung terhadap member lain ataupun user yang tidak terdaftar. Sebelum menggunakan fasilitas yang disediakan member harus login. Member dapat upload produk dan membuat produk berdasarkan kategori yang disediakan serta mengelola infomasi produk tersebut. Member juga diberikan hak untuk menjadi teman dari member lain. Member dapat menuliskan newsletter yang dapat dikomentari oleh member lain yang menjadi teman dan dilihat oleh member yang bukan teman. Member dapat berkirim pesan ke member lainnya dan complaint ke admin jika terjadi hal hal yang dirasa merugikan. Sedangkan admin dapat meng-update status keanggotaan user, dapat mengolah data member, kategori, komplain, data want to sell dan want to buy dengan melakukan login terlebih dahulu sebelum masuk ke halaman admin. Dari ilustrasi tersebut dapat diketahui objek-objek yang terlibat beserta atribut dan operasi setiap objeknya, objek-objek ini kemudian dibangun dalam diagram high-level class.

\section{Analysis}

Pada segmen analisis ini akan dibahas dua aksi yaitu identifikasi kebutuhan sistem dan identifikasi kelas. Pada segmen ini digunakan diagram use case, diagram class dan diagram sequence.

a. Identifikasi Kebutuhan Sistem

Berdasarkan studi pustaka buku Konsep dan aplikasi E-Bussines karangan DR. Richardus Eko Indrajit, Buku Principles of Marketing karangan Philip kotler dan Gery Armstrong serta buku Internet Marketing Building Advantage In A Nerworked Economy karangan Raffi A Mohammed, studi internet mengenai pasar elektronik dan analisis yang telah dilakukan pada tahap perencanaan kebutuhan maka terdapat dua utama aktor dan satu aktor tambahan, member dan admin serta user dan 24 use case, yaitu olah data newsletter, testimoni, olah data login, olah data pesan, olah data produk, olah data profile, komplain, add partner bussines, mendaftar 
penjual, mendaftar pembeli, searching, daftar member, olah data kategori, olah data komplain, olah data penjual, olah data pembeli. Gambar arsitektur sistem dapat dilihat pada Gambar 1. Gambar diagram Use Case untuk model aplikasi E-Market dapat dilihat pada Gambar 2.

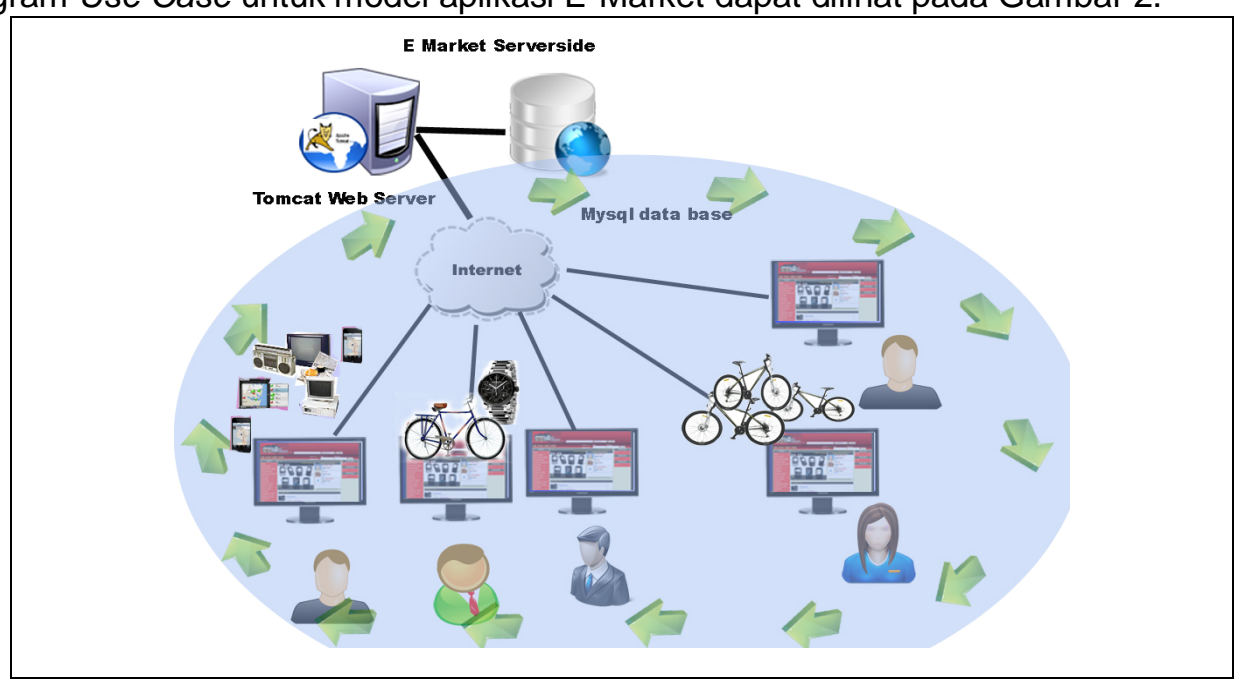

b. Identifikasi Kelas

Gambar 1. Arsitektur Sistem

Gambar identifikasi kelas dapat dilihat pada gambar 3.

c. Diagram Sequence

Diagram yang mempresentasikan squensial dari hubungan low level kelas dari actor ke case atau kegiatan yang digambarkan oleh diagram usecase. Pada Gambar 4 user request daftar menjadi member dan akan dieksekusi method daftar() pada kelas $C$ daftar kemudian berlanjut memanggil method chekUser untuk melihat apakah nama member sudah di pakai jika belum maka proses daftar akan berlanjut lagi dengan mengeksekusi method daftar() jika data yang di hasilkan bernilai valid artinya belum ada user yang sama dengan user yang ada didatabase semua dicontrol oleh kelas Cdaftar, kemudian hasil akan disimpan ke database.

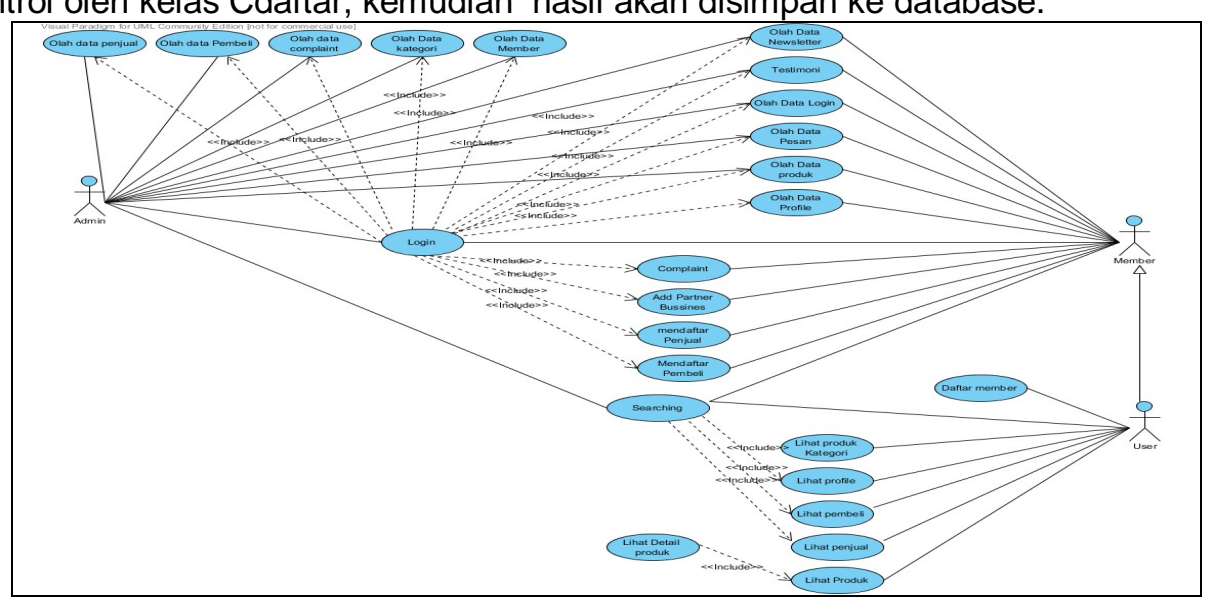

Gambar 2. UseCase 
3. Design

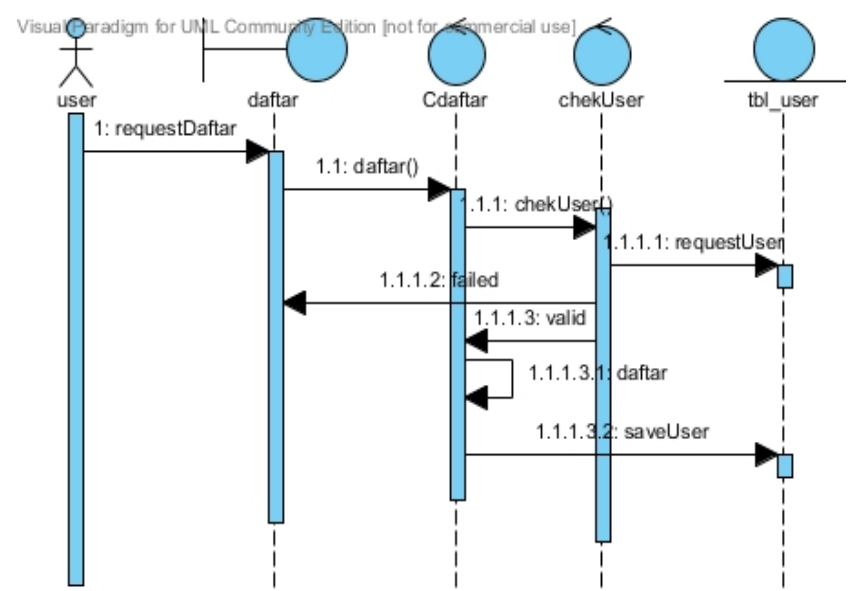

Gambar 3. Diagram Sequence Daftar Member

Dalam perancangan dilakukan empat tahapan yaitu perancangan software atau tata letak yang disimbolkan dengan diagram deployment, perancangan database, perancangan struktur menu dan perancangan antarmuka.

a. Perancangan Deployment Diagram

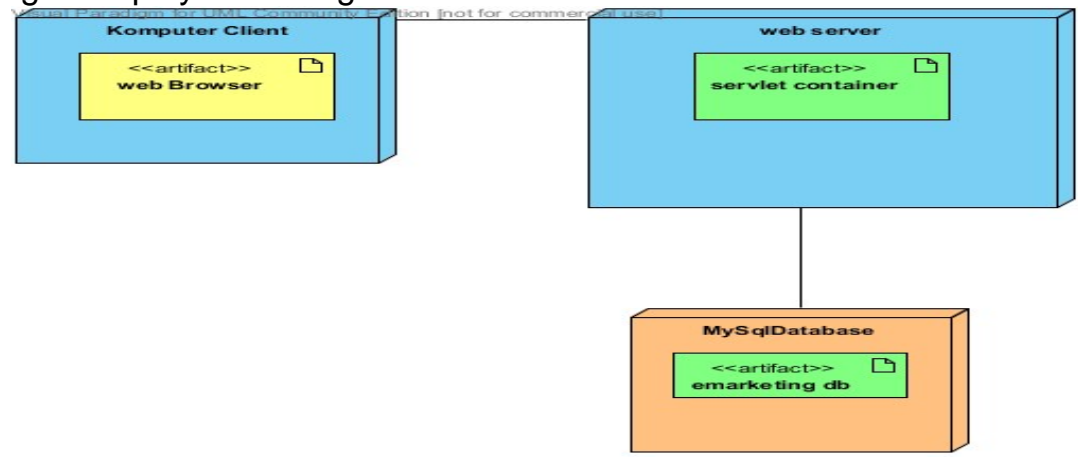

Gambar 4. Diagram Deployment Aplikasi E-market

Diagram ini menjelaskan pemetaan atau rancangan jalannya software. Pertama client mengakses web browser lewat komputernya kemudian request akan ditanga[ni dan diproses web server melalui servlet container permintaan akan diolah oleh servlet container dan dikembalikan ke web browser client. Servlet container akan berhubungan langsung dengan database untuk mengolah permintaan dan sebagai bussines logic.

b. Perancangan Database

Perancangan database dibagi menjadi dua, yaitu perancangan model entity relation dan perancangan tabel. Rancangan model entity relation dapat dilihat pada gambar 6 .

c. Rancangan Struktur Menu User

Rancangan struktur menu terdiri dari struktur menu user, struktur menu member dan struktur menu admin.

4. Development

Development merupakan segmen penerapan model dan diagram yang telah terbentuk, antara lain dengan melakukan pengembangan source code, pengecekan source code, serta pembuatan user interface.

5. Deployment

Deployment merupakan segmen terakhir yang dilakukan setelah development. Sistem yang terbentuk akan diintegrasikan dengan hardware maupun dengan sistem operasi yang digunakan. 


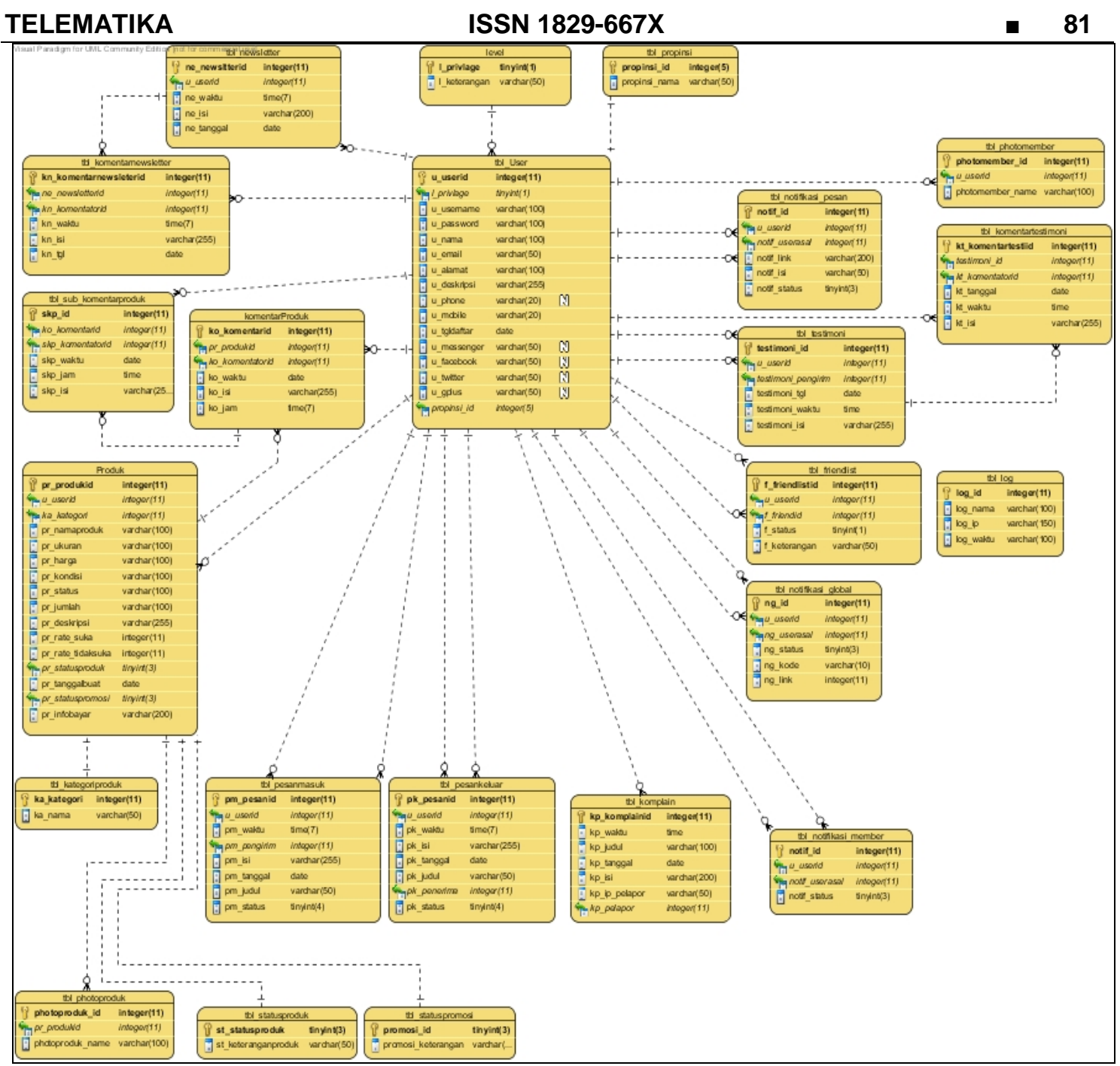

Gambar 5. ERD (Entity Relational Diagram) 


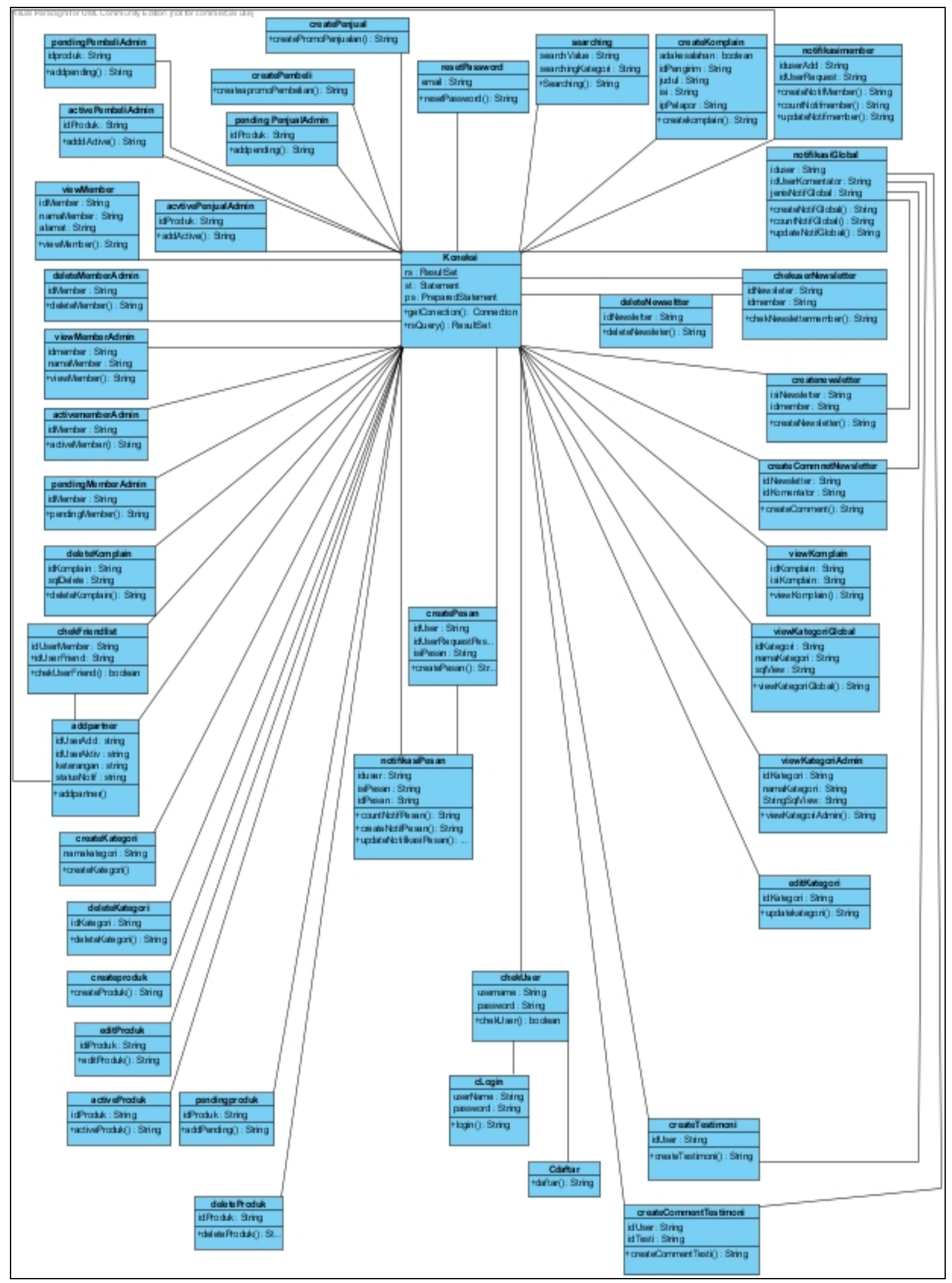

Gambar 6. Low-level class diagram untuk aplikasi E-Market 


\section{HASIL DAN PEMBAHASAN}

Berikut beberapa hasil implementasi dari aplikasi yang dibangun. Gambar 7 merupakan tampilan halaman pengunjung yaitu halaman yang dibuka pertama kali ketika web dibuka. Terdapat beebrapa menu seperti menu penjual, lihat gudang, produk berdasar kategori. Selain itu juga terdapat beberapa fasilitas lainnya dan form login.

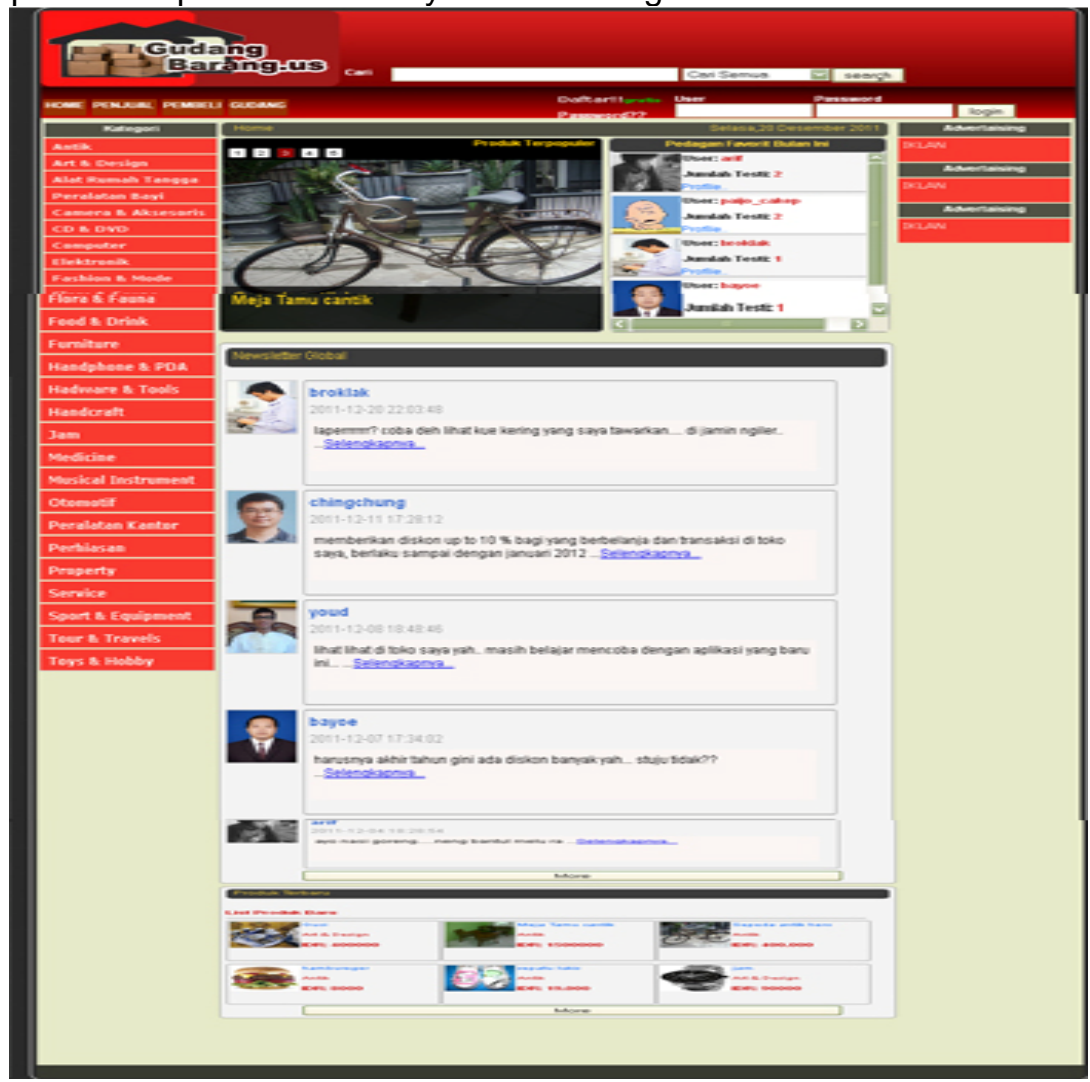

Gambar 7. Tampilan halaman home pengunjung

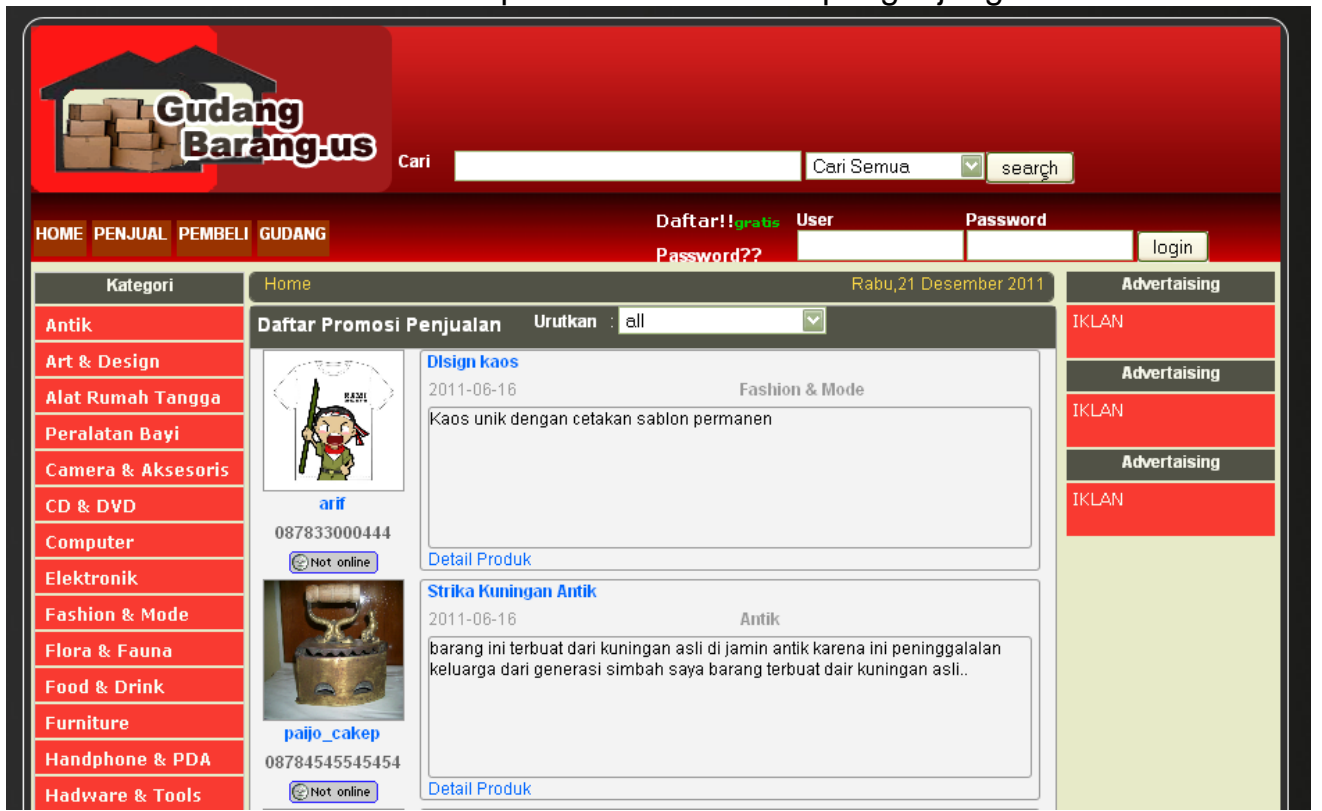

Gambar 9. Halaman Promo Penjualan

Gambar 9 merupakan tampilan untuk memasukkan produk yang ada dan dikategorikan berdasar jenis produk, pada halaman ini juga bisa di setting produk tersebut akan akan dipromosikan sebagai promo penjualan atau promo pembelian. 


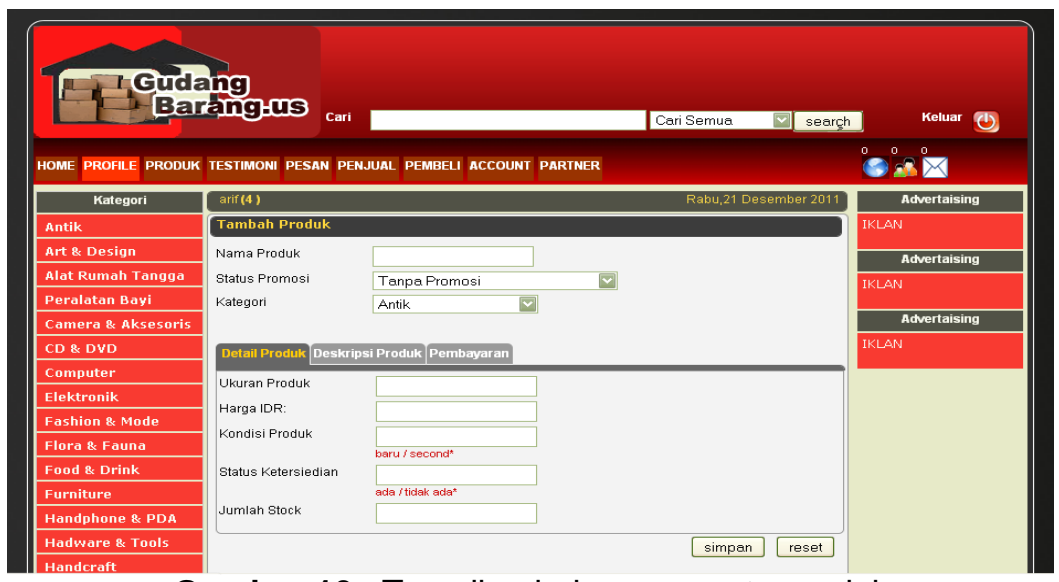

Gambar 10. Tampilan halaman create produk

\section{Kesimpulan}

Setelah melewati berbagai proses sesuai dengan metode GRAPPLE Telah berhasil dibangun Model Aplikasi E-Marketing Sebagai Sarana Promosi Dan Tukar Menukar Informasi Antara Penjual Dan Pembeli, Aplikasi ini menyediakan wadah dan ruangan bagi para penjual dan pembeli yang ingin mengembangkan dan memperluas pangsa pasar nya, tidak hanya menjual barang saja, tetapi secara sosial hubungan pertemanan dan relasi semakin banyak, karena aplikasi ini menyediakan fasilitas untuk memungkinkan terjadinya pertukaran informasi tidak hanya tentang produk yang di tawarkan saja bahkan lebih dari itu,Sehingga berjualan lebih menyenangkan dan mengasyikkan .

\section{DAFTAR PUSTAKA}

Aji,Digda A., 2009, Kardinalitas desain data dengan ERD.

$<$ http://digda.blog.uns.ac.id/2009/04/26/desain-data-menggunakan-erd/simbol/>

(diakses 27 Desember 2010).

Fatansyah,2004, Basis Data, Informatika, Bandung.

Fowler, M., 2005, UML Distilled Edisi 3 Panduan Singkat Bahasa Pemodelan Objek Standar, Andi, Yogyakarta.

Hartati, Sri W,dkk ,2007, Pemrograman Java Servlet dan JSP dengen Netbeans, Andi, Yogyakarta.

Hartono, J, 1999, Sistem Informasi Bagian I, PT Wahana Komputer, Semarang.

Harrington., L, Jan, 2009, Relational Database Design and Implementation thrid editon, Morgan Kaufmann, Burlington.

Indrajit, Richardus E, 2011, Konsep Dan Aplikasi E-Business .

<http://www.scribd.com/doc/73460953/3/EVOLUSI-E-MARKETPLACE>,(diakses november 2011).

Kadir, Abdul, 2003, Pengenalan Sistem Informasi, Andi, Yogyakarta.

Kadir, Abdul, 2004, Dasar Pemrograman Java 2, Andi, Yogyakarta.

Kadir, Abdul, 2004, Dasar Pemrograman Web Dinamis dengan JSP(Java Server Page), Andi, Yogyakarta.

Kadir, Abdul, 2009, Dasar Perancangan \& limplementasi Database Relational, Andi, Yogyakarta.

Kotler, Philip., Armstrong, Gary, 2004, Principles of Marketing. 10th edition, Prentice Hall, New Jersey.

Kurniawan, Yohanes., 2010 E-Marketing Sebagai Alat Bantu Dalam Memperluas Segmen Pasar.

<http://y2kgood.files.wordpress.com/2009/06/dipindah-ke-pdf21.pdf>, $\quad$ (di akses 12 November 2010) .

Mohammed, Rafi A., et al. 2003. Internet Marketing Building Advantage In A Nerworked Economy, Second Edition, McGraw-Hill/Irwin, New York.

Rickyanto, Isak, 2004, Pemrograman Web dengan Java Servlet, Andi, Yogyakarta.

Schmuller, Joseph, 1999, Teach Yourself UML in 24 Hours, San Publising, Indianapolis.

Strauss, Judy., Frost Raymond, 2001, E-Marketing $2^{\text {nd }}$ Edition, Prentice Hall, New Jersey. 